\title{
Refinements in the use of equivalent latitude for assimilating sporadic inhomogeneous stratospheric tracer observations, 2: Precise altitude-resolved information about transport of Pinatubo aerosol to very high latitude
}

\author{
P. Good ${ }^{1}$ and J. Pyle ${ }^{2}$ \\ ${ }^{1}$ Institute of Environmental Research and Sustainable Development, National Observatory of Athens, Greece \\ ${ }^{2}$ Centre for Atmospheric Science, Cambridge, UK
}

Received: 2 December 2003 - Published in Atmos. Chem. Phys. Discuss.: 29 January 2004

Revised: 31 August 2004 - Accepted: 2 September 2004 - Published: 13 September 2004

\begin{abstract}
From high latitude lidar observations, quite precise information is extracted about the temporal evolution and vertical distribution of volcanic aerosol in the high latitude lower stratosphere following the eruption of Mount Pinatubo. Irreversible mixing of lower stratospheric aerosol, to the arctic pole during early 1992 , is demonstrated, as a function of potential temperature and time. This work complements previous studies, which either identify vortex intrusions - without demonstrating irreversible transport, or use lower resolution satellite observations. The observed transport is associated tentatively with the vortex disturbance during late January, 1992. A very large number of high resolution lidar observations of Mount Pinatubo aerosol are analysed, without any data averaging. Averaging in measurement or analysis can cause tracer mixing to be overestimated. Averaging in the analysis can also require assumptions about which quantity has the dominant error (in this case, the equivalent latitude coordinate or the measurement), and which part of the data contains real structure. The method below attempts to avoid such assumptions.
\end{abstract}

\section{Introduction}

The environmental effects of anthropogenic emissions into the atmosphere are strongly dependent on the transport of photochemical constituents. For example, a crucial factor controlling the depletion of stratospheric ozone is the strength of the winter polar vortex (e.g. Chipperfield and Jones, 1999; Millard et al., 2002). Constituents act as dyelike tracers of transport. Tracer transport timescales vary greatly, eg. with rapid transport parallel to the vortex but very

Correspondence to: P. Good

(pgood@meteo.noa.gr) slow transport across it. The strength of the vortex as a transport barrier varies with altitude (McIntyre, 1995), although details of this variation are difficult to ascertain. The vortex distorts continuously, exhibiting very fine scale features (e.g. Plumb et al., 1994) and so its position and size cannot be precisely known. Also, at lower altitudes the vortex is weaker and more difficult to identify. Ground-based or in-situ tracer observations tend to be sporadic and inhomogeneous, while satellite data averages over much larger atmospheric volumes. Measuring significant tracer transport, by comparing sets of measurements with themselves and with model results, then, is not straightforward. Convincing identifications have been made of vortex intrusions occurring in the real atmosphere (particularly Plumb et al. (1994) and Manney et al. (1998) who find agreement between high resolution model and observational data), although these studies cannot show the intrusions actually mixing down irreversibly into the vortex centre. Plumb et al. (2000) presented tracer-tracer correlation plots from satellite data, which indicate gradual mixing of air into the 1992/93 Arctic vortex. Lee et al. (2001) use satellite observations, at 480K, of a dehydrated 1992 Antarctic vortex, maintained even after temperatures rose above the frost point. Their data appears to show some mixing into the vortex by November, prior to the vortex breakup. The results below complement these satellite data studies, by analysing, without averaging, a large number of high resolution aerosol lidar observations of the early 1992 mid- and high northern latitude stratosphere. Averaging in measurement or analysis can cause tracer mixing to be overestimated. Averaging in the analysis can also require assumptions about which quantity has the dominant error, and which part of the data contains real structure. 
The June 1991 eruption of Mount Pinatubo provided a useful opportunity to study the arctic polar vortex transport barrier. Russell et al. (1996) summarize the observations of the resulting stratospheric aerosol. A tropical cloud of liquid binary $\mathrm{H}_{2} \mathrm{SO}_{4} / \mathrm{H}_{2} \mathrm{O}$ was formed (McCormick and Veiga, 1992; Deshler et al., 1992) over a timescale of about one month (Bluth et al., 1992; Read et al., 1993), which then spread to midlatitudes (McCormick and Veiga, 1992; Trepte et al., 1993). In northern midlatitudes, the aerosol loading peaked around December 1991 and then decayed slowly - with a timescale of about 300 days (Grant et al., 1996; Langford et al., 1995). Thus, by early 1992, the northern midlatitude stratosphere contained a relatively stable reservoir of aerosol. The timing of the eruption meant that northern high latitudes remained relatively free of volcanic aerosol throughout the winter 1991-92 (Neuber et al., 1994). The vortex was, however, rather disturbed during January 1992 (Plumb et al., 1994). Plumb et al. (1994) identified, in both observed data and model results, a filamentary vortex intrusion that may have caused transport of midlatitude air into the vortex. The aim of the analysis below is to try and identify irreversible aerosol transport into the 1991-92 northern vortex, by reexamining the available lidar data.

The analysis uses a diagnosed equivalent latitude coordinate. Meridional coordinates based on the area enclosed by contours of potential vorticity (PV) or other tracers have been used (e.g. Butchart and Remsberg, 1986; Nakamura, 1996), since the area enclosed by a tracer contour evolves much more slowly than reversible deformations in its shape. Butchart and Remsberg (1986) defined the "equivalent latitude" for PV, but it is expressed more generally as $\phi_{e}=\sin ^{-1}(1-2 A(\chi))$, where $A(\chi)$ is the area enclosed by a tracer contour of value $\chi$, on a normalised sphere. Nakamura (1996) showed that two dimensional transport can be written in a contour area coordinate as a diffusion. Long lived tracers tend to show relatively tight correlations, due to the rapid local mixing processes (Plumb and Ko, 1992), so it is reasonable to use equivalent latitude calculated from a single long lived tracer as an approximate meridional coordinate. In the text below, the "error" in diagnosed equivalent latitude $\left(\phi_{e}\right)$ is referred to. By "error", we mean the degree to which the contours of $\phi_{e}$ misalign with the contours of the observed tracer (or more precisely, the tracer that would be observed in the absence of any measurement error). The quality of this equivalent latitude coordinate is assessed, against vortex edge observations, in Good and Pyle (2004).

From the aerosol lidar data described below, an approximately conserved tracer mixing ratio $\left(v_{R}\right)$ may be inferred. The target of this study is to estimate the quasi-vertical profile of the quantity $v_{R}^{(h)} \cdot v_{R}^{(h)}$ is defined as a function of potential temperature $(\theta)$, and is the true value of $v_{R}$ at the highest equivalent latitudes. By "true", we mean in the absence of any errors. The "highest equivalent latitudes" are deep within the vortex (where it is present), and will tend to occur at high geographic latitude although not in general directly over the pole. The "highest equivalent latitudes" might be defined as the air on an isentropic surface which is most strongly isolated fluid dynamically from the mid-latitudes. This profile is not physically vertical, since the location of the highest equivalent latitude varies with potential temperature, especially in the northern hemisphere where the polar vortex is strongly disturbed. An increase over time in $v_{R}^{(h)}$ on a given $\theta$ surface must indicate irreversible transport of aerosol into the vortex on that $\theta$ surface, or descent from above. In estimating $v_{R}^{(h)}$, only weak assumptions are made about the errors in $\phi_{e}$. This is enabled by the large number of observations taken at high latitude.

\section{Measurements and Model}

\subsection{Observed data}

This analysis uses ground-based $532 \mathrm{~nm}$ aerosol lidar observations taken at six sites at mid- and high northern latitudes during the EASOE campaign of winter 1991-92. The measurements are available on the EASOE CD-ROM. See Table 1 for locations and references describing the measurement data. The vertical resolution is mostly of $200 \mathrm{~m}$ or less, or about $4 \mathrm{~K}$ in the lower stratosphere. This is equivalent (Haynes and Anglade, 1997) to about 50km in the horizontal.

From the aerosol backscatter ratio (R), the best estimate of a conserved tracer mixing ratio ( $v_{R}$, or "lidar tracer") is (see Bohren and Huffman (1981) and the references in Table 1):

$v_{R}=\mathrm{R}-1=\frac{\mathrm{B}_{(a e r)}}{\sigma_{(m o l)} \mathrm{n}_{(m o l)}}=\frac{1}{\sigma_{(m o l)}} \frac{\mathrm{B}_{(a e r)}}{\mathrm{n}_{(m o l)}}$

where $\mathrm{R}$ is the backscatter ratio, $\mathrm{B}_{(a e r)}$ is the aerosol backscatter, $\sigma_{(\mathrm{mol})}$ the molecular scattering cross-section and $\mathrm{n}_{(m o l)}$ the air number density. Brock et al. (1993) and Jager et al. (1995) used observed aerosol size distributions to show that for the case of $532 \mathrm{~nm}$, lidar backscatter ratio is a good predictor (to within 5\%) of aerosol mass mixing ratio during late 1991 through early 1992.

The only sulphate aerosol microphysical processes significantly modifying mass mixing ratio during early 1992 (Russell et al., 1993) were water vapour uptake, PSC formation and gravitational sedimentation. The effects of water vapour uptake on the lidar observations was estimated using standard thermodynamic data (Hanson et al. (1994) parameterise the data of Steele and Hamill (1981)) and Mie backscatter calculations (see Bohren and Huffman, 1981). This effect is negligible for these specific observations, since the regions of cold temperatures either had very low volcanic aerosol content or were not sampled by the observations. The northern winter 1991-92 saw only a short period of low stratospheric temperatures between late December 1991 and mid January 1992; this was too warm for PSC II (eg. Farman et al., 1994). The observation of PSCs of any type during early 
Table 1. References for the EASOE lidar data.

\begin{tabular}{llll}
\hline Site & Position & Citation & $\begin{array}{l}\text { Author of } \\
\text { CD-ROM data }\end{array}$ \\
\hline Haute-Provence & $44.5^{\circ} \mathrm{N}, 5.5^{\circ} \mathrm{E}$ & Chazette et al. (1995) & S. Godin \\
Aberystwyth & $52.4^{\circ} \mathrm{N}, 355.9^{\circ} \mathrm{E}$ & Vaughan et al. (1994) & G. Vaughan \\
Sodankyla & $67.4^{\circ} \mathrm{N}, 26.6^{\circ} \mathrm{E}$ & Stein et al. (1994) & L. Stefanutti \\
Andoya & $69.3^{\circ} \mathrm{N}, 16.0^{\circ} \mathrm{E}$ & Schafer et al. (1994) & K. H. Fricke \\
Thule & $76.5^{\circ} \mathrm{N}, 291.2^{\circ} \mathrm{E}$ & Digirolamo et al. (1994) & G. Fiocco \\
Ny-Ålesund & $78.9^{\circ} \mathrm{N}, 11.9^{\circ} \mathrm{E}$ & Beyerle and Neuber (1994) & R. Neuber \\
\hline
\end{tabular}

1992 was relatively infrequent, and PSC Ia are identified by high depolarisation and return relatively low backscatter signals (Browell et al., 1990). Plots of backscatter ratio versus analysed temperature for the early 1992 lidar data show PSC Ib only over Andoya on 9 January. This PSC was also observed by the ISAMS satellite instrument (Massie et al., 1997). These observations were removed before analysis. Sedimentation rates may be estimated (G. Brasseur and Tyndall, 1999) using observed size distributions (e.g. Deshler et al., 1993; Deshler, 1994). Sedimentation is discussed later, in the context of the specific results.

The random error in the lidar data was estimated empirically at about $10-20 \%$ in R. This estimate used the scatter of values measured within the midlatitude surf-zone, with the mean vertical gradient removed. Horizontal tracer gradients are small within the surf-zone, so measurement error dominates over equivalent latitude error. This is consistent with reported theoretical error estimates (references in Table 1).

\subsection{Equivalent latitude}

Equivalent latitude fields are estimated from passive tracers, initialised with Ertel PV and then transported by the SLIMCAT isentropic model [described by Chipperfield (1999)] forced by United Kingdom Meteorological Office analyses (described by Swinbank and O'Neill, 1994). SLIMCAT uses the Prather advection scheme (Prather, 1986). Diabatic heating was set to zero, and horizontal transport calculated on each of 10 isentropic levels in the lower stratosphere, from $350 \mathrm{~K}$ to $520 \mathrm{~K}$, spaced by about $2 \mathrm{~km}$. The horizontal resolution was $5.6^{\circ}$ in longitude and $2.5^{\circ}$ in latitude. For each measurement location and time, equivalent latitude was calculated from a PV tracer which had been initialised with PV 4-5 days earlier and then transported by SLIMCAT until the time of the observation. The quality of this equivalent latitude coordinate is assessed, against vortex edge observations, in Good and Pyle (2004). Substantial errors are expected in the diagnosed equivalent coordinate at the lower potential temperatures in particular due to diabatic transport in the real atmosphere. Large errors also occur at high latitude as the vortex becomes progressively weaker, more distorted and hence more difficult to model below about $475 \mathrm{~K}$. The analysis method is designed with these large errors in mind.

\subsection{Scatter plots}

Figures 1 and 2 show scatter plots of $v_{R}$, for the first 80 days of 1992. The frequency of observations outside this period was too low for the purposes of this analysis. Averaging or other manipulation is avoided, in order to avoid making unwarranted assumptions about the errors involved.

\subsection{1 $v_{R}$ versus $\phi_{e}$}

Figure 1 plots $v_{R}$ against $\phi_{e}$, for a stack of non-overlapping potential temperature bins. Two time bins are used: days 0-40 and 41-80 of 1992 (1 January-10 February and 11 February-20 March 20). The greatest attention is on the region below about $440 \mathrm{~K}$, where high latitude structure is significant and complex. Six $10 \mathrm{~K} \theta$ bins span the interval between $350 \mathrm{~K}$ and $440 \mathrm{~K}$. Note that for $96 \%$ of the observations, the vertical resolution of the measurements is better than $4 \mathrm{~K}$ at these values of $\theta$. One $475-520 \mathrm{~K}$ bin represents the region above $475 \mathrm{~K}$. Two bins fill the gap between $440 \mathrm{~K}$ and $475 \mathrm{~K}$. Note the variable density of observations at different values of $\phi_{e}$. This is particularly significant for days $0-40$. However, the sampling at large equivalent latitudes is extremely good.

At the higher potential temperatures, these plots largely show the high-intermediate-low values expected for an equivalent latitude section cutting through the vortex edge (since the volcanic eruption occurred at low latitudes). The midlatitude profile is roughly the same for the two time bins. The vortex above $475 \mathrm{~K}$ is largely clean of volcanic aerosol. Note that the vortex edge step (around $\phi_{e} \approx 75^{\circ}$ ), for days $41-80$ above $475 \mathrm{~K}$, is broad: about $10^{\circ}$ wide, in $\phi_{e}$. This subset of the data was taken after the late January vortex disturbance. This disturbance could have caused mixing within the vortex edge region, broadening the vortex edge step signature in $v_{R}$, even if significant transport into the vortex centre is not observed. Detailed time-resolved transport between $475-520 \mathrm{~K}$ is presented in Good and Pyle (2004). 
$\nu_{R}$ versus equivalent latitude

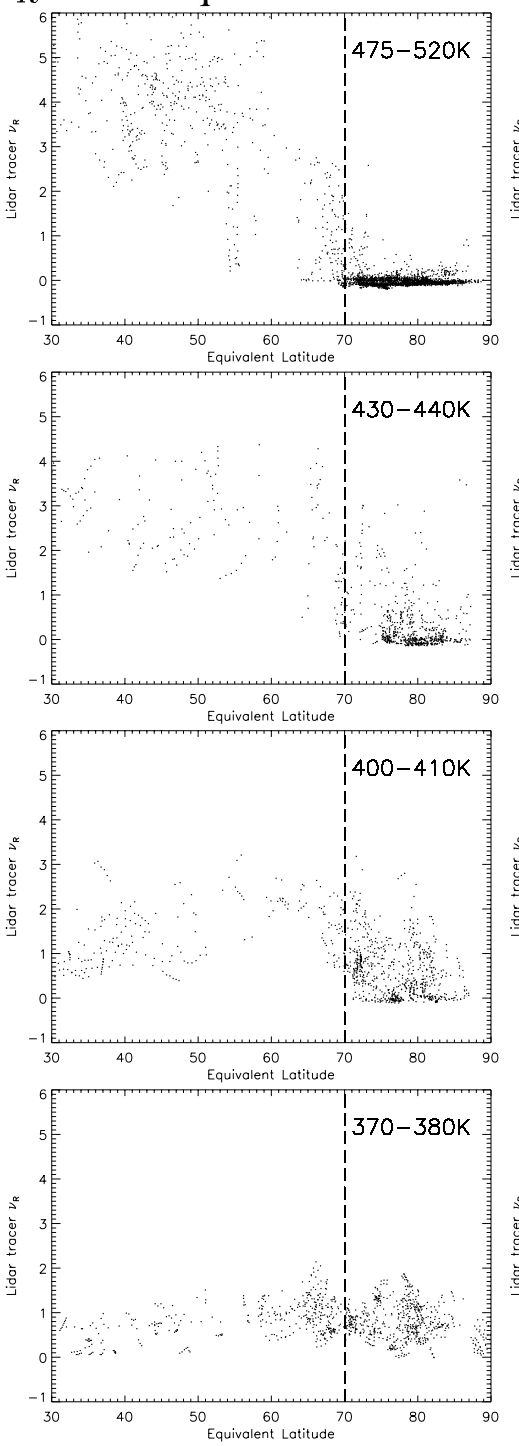

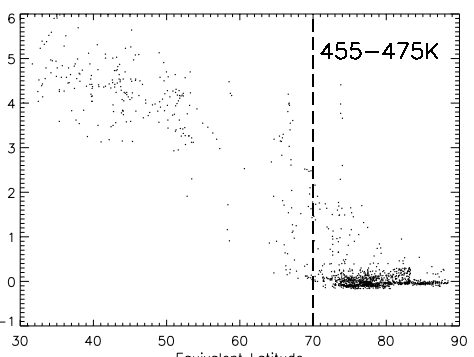
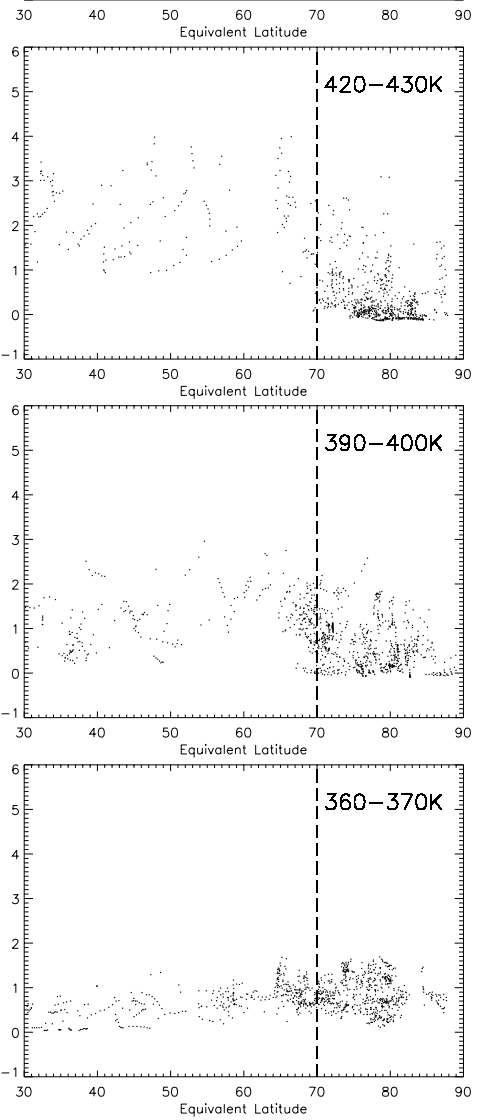

Days 0 to 40
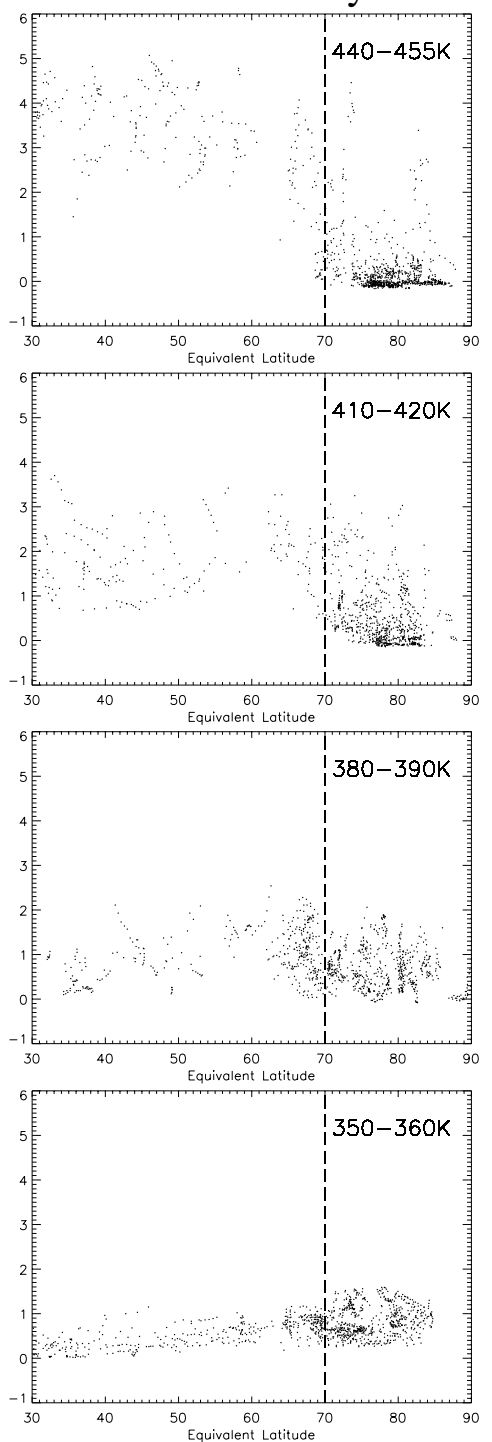

Fig. 1. $v_{R}$ versus equivalent latitude. Upper half: days 0-40; lower: days 41-80. Each plot represents a different potential temperature $(\theta)$ window. At high $\theta$, a clear separation is seen between dense aerosol at midlatitude and the clean vortex air.

$\phi_{e}$ shows some success in separating mid- and high latitude observations. In some plots, especially at low $\theta$, the $\phi_{e}$ coordinate is also able to resolve a meridional gradient within the midlatitudes. This is the case where $\theta \lesssim 420 \mathrm{~K}$ for days $0-40$, and $\theta \lesssim 400 \mathrm{~K}$ for days $41-80$. This positive gradient of $v_{R}$ with $\phi_{e}$ can be explained by the fact that wintertime diabatic descent is faster at higher latitudes, and that $v_{R}$ is increasing with altitude. Faster diabatic descent means that larger tracer values are brought down at higher midlatitudes than at lower midlatitudes.

As $\theta$ decreases below $520 \mathrm{~K}$, the distinction between midand high latitudes becomes less apparent. This is partly because the midlatitude tracer burden decreases strongly with decreasing potential temperature. At the same time, elevated
$v_{R}$ values appear at high $\phi_{e}$ at lower levels, most clearly in the day 41-80 bin and below about $440 \mathrm{~K}$. At the lowest levels, there are in fact higher values of $v_{R}$ towards the polar regions than in midlatitudes. These elevated tracer values at high latitude were presumably caused by a combination of rapid diabatic descent at high latitude and poleward mixing becoming increasingly strong below $475 \mathrm{~K}$.

Figures 1 and 2 show a large degree of scatter, due to the combined errors in $v_{R}$ and $\phi_{e}$ and $\theta$. If all three quantities were known exactly, the plots would show compact curves. $\theta$ error is not expected to be large. Particular care is required when interpreting observations of elevated $v_{R}$ at high equivalent latitude, as they may represent midlatitude or vortex edge air, misplaced by equivalent latitude error. 
$\nu_{R}$ versus equivalent latitude

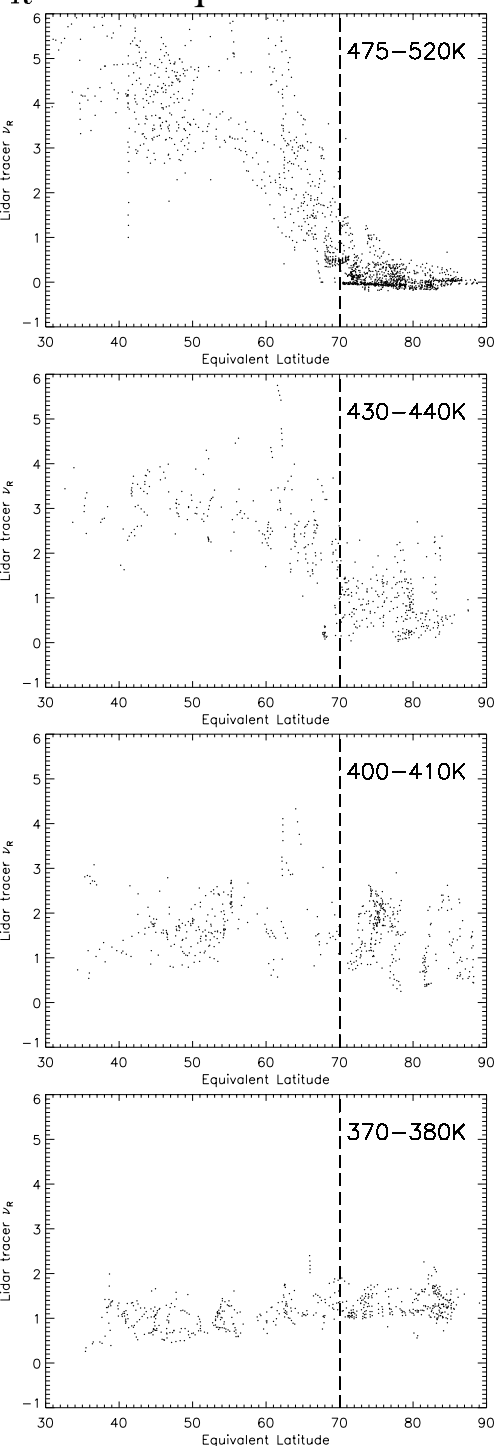

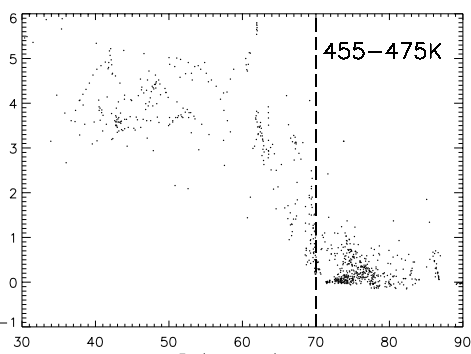
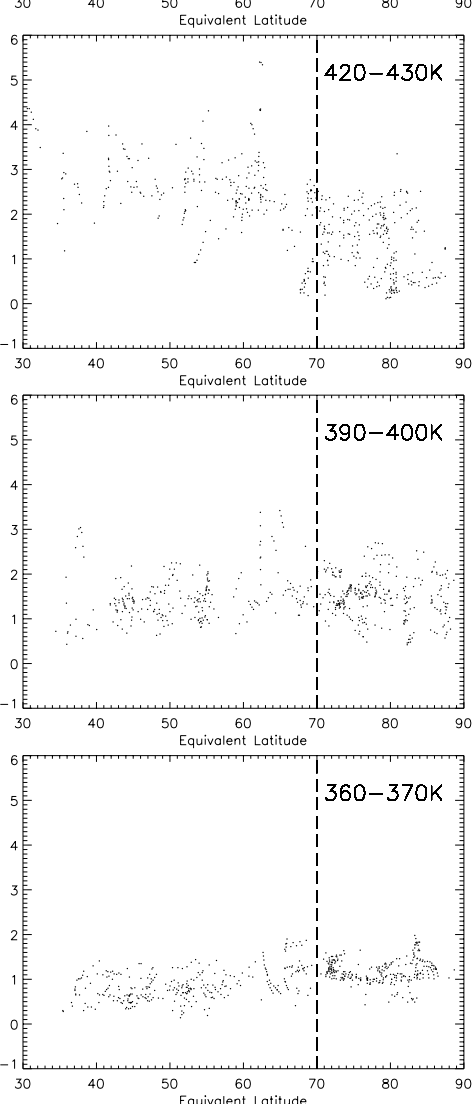

Days 41 to 80
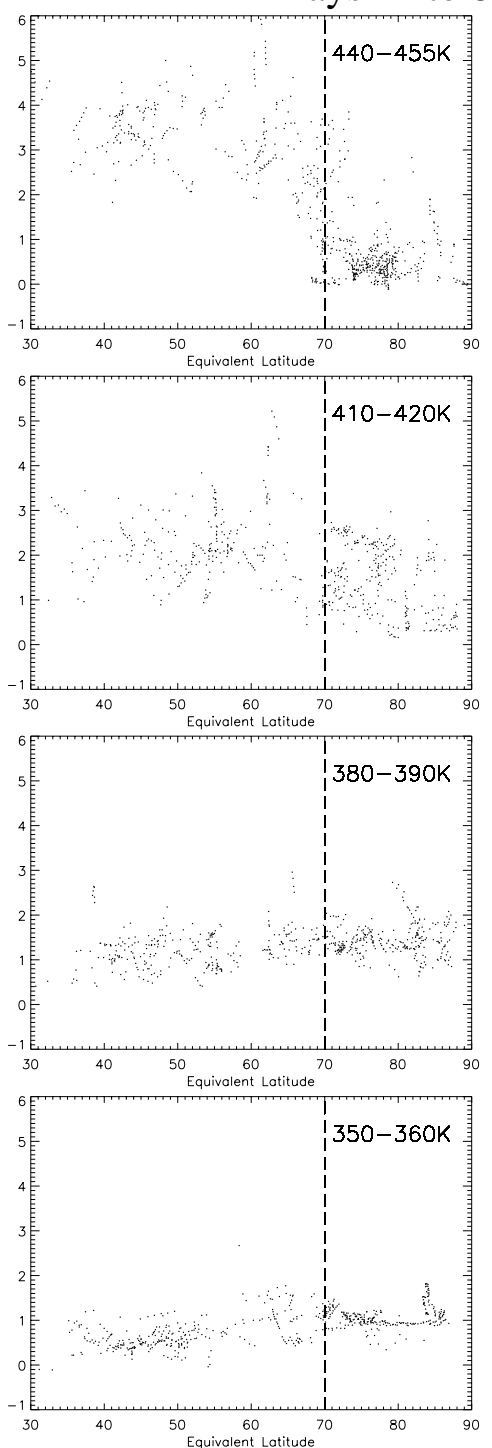

Fig. 1. Continued.

\subsection{2 $v_{R}$ versus time}

The $v_{R}$ versus time plots of Fig. 2 show only data for $70<\phi_{e} \leq 90$. Figure 1 shows that $\phi_{e} \approx 70$ largely bounds the extent of characteristic high latitude observations (low $v_{R}$ ). The potential temperature bins are the same as those in Fig. 2.

Above about $410 \mathrm{~K}$, the time evolution at high latitude is rather masked by the scatter. In particular, the minimum $v_{R}$ values above $475 \mathrm{~K}$ remain at or below zero throughout. However, in all the plots up to at least $430 \mathrm{~K}$, and starting from about day 40, an increase in minimum $v_{R}$ values is evident. There is a hint that this increase is roughly linear over days 40 through 80 , but the sampling is sparse after day 63 .

This change in high latitude $v_{R}$ after day 40 provided the reason for binning the data into days $0-40$ and $41-80$ for
Fig. 1. Note that there are few observations between days 41-47 and between days 64-80.

\section{Method for estimating $v_{R}^{(h)}$}

This section aims to specify an appropriate method for estimating $v_{R}^{(h)}$ : the true value of $v_{R}$ at the highest equivalent latitudes. This involves error minimisation, and so requires knowledge of the errors involved. For $\phi_{e}>70$, the scatter of $v_{R}$ measurements is particularly large near $430 \mathrm{~K}$. The contributing errors in this region are investigated, confirming that $\phi_{e}$ error dominates, prior to specifying a method to estimate $v_{R}^{(h)}$. 


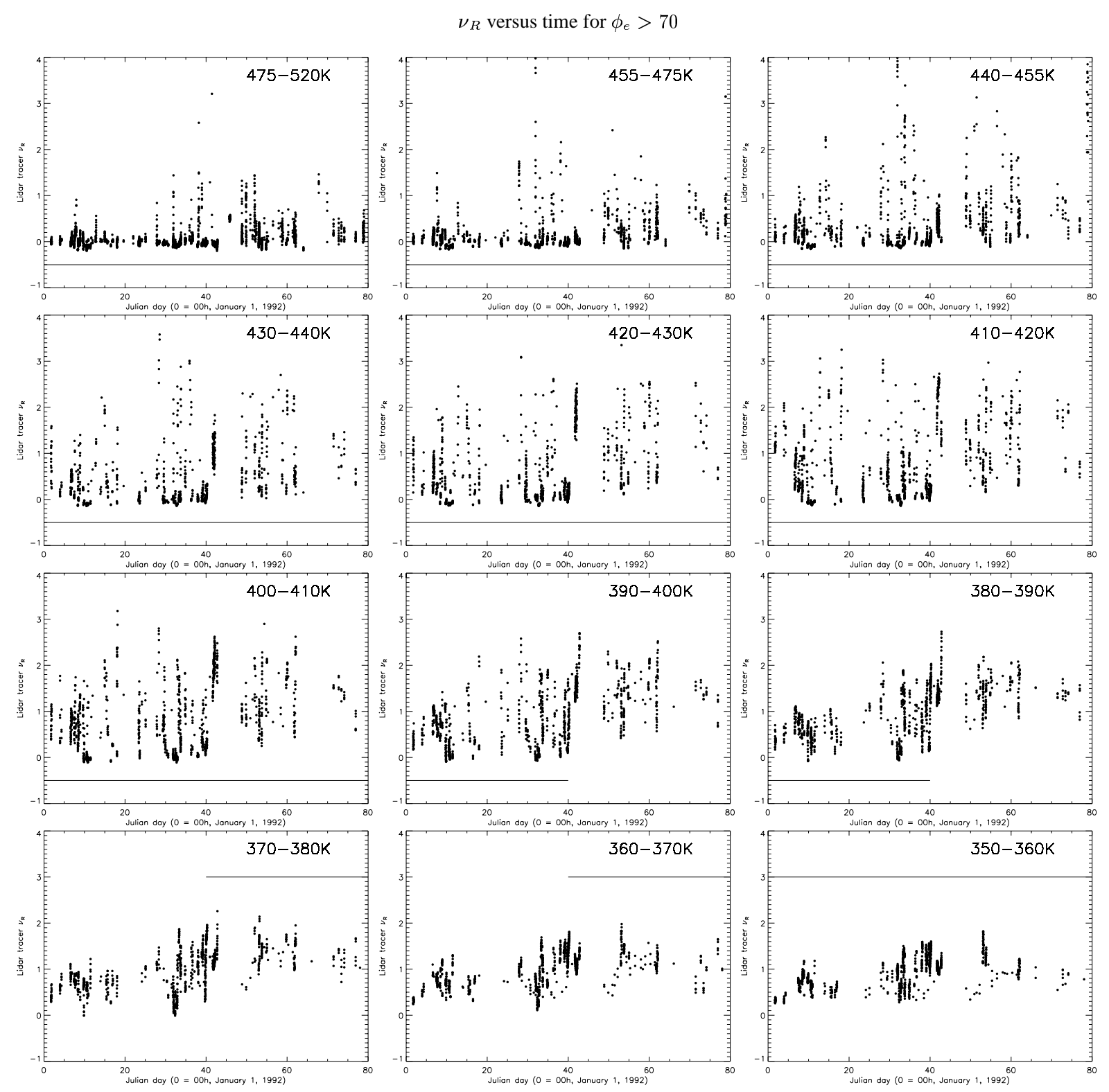

Fig. 2. $v_{R}$ versus time, for observations where $\phi_{e}>70$. Each plot is for a different potential temperature window (as in Fig. 1). These plots should be compared with Fig. 1 . For $\theta>380 \mathrm{~K}$, the attention is on the time evolution of the minimum values of $v_{R}$, which show an increase after day 40 . For $\theta<380 \mathrm{~K}$, the attention is on the time evolution of the maximum values of $v_{R}$, which show some signs of increase after about day 30. The significance of the minimum and maximum values, and the horizontal lines are explained in detail later in the text.

\subsection{Explaining the scatter at high $\phi_{e}$ near $430 \mathrm{~K}$}

At high $\phi_{e}$ near $430 \mathrm{~K}$, the scatter in $v_{R}$ is much larger than the expected measurement error. Figure 3 is used to demonstrate the importance of equivalent latitude error in causing the large scatter in $v_{R}$ for $\phi_{e}>70$ near $430 \mathrm{~K}$. In this section we study the properties of the complete lidar vertical soundings. That is, we use the fact that all observations in a single sounding form a vertical profile which is taken almost simultaneously. We aim to show that the profiles can be divided very roughly into two clusters, with differing characteristics. It is not possible to rigorously allocate specific profiles to specific clusters. The aim is simply to show that there are two statistically-distinct clusters, and to explain why. To start with, each vertical profile of $v_{R}$ was characterised by four quantities: $v_{R}$ at $430 \mathrm{~K} ; v_{R}$ at $355 \mathrm{~K}$; the $v_{R}$ profile maximum; and the potential temperature at which the $v_{R}$ profile maximum occurs. The three plots in Fig. 3 use these values as axes. The solid lines in Figs. $3 \mathrm{~b}$ and $3 \mathrm{e}$ trace the mean, maximum and minimum profiles of $v_{R}$ at midlatitude. The 


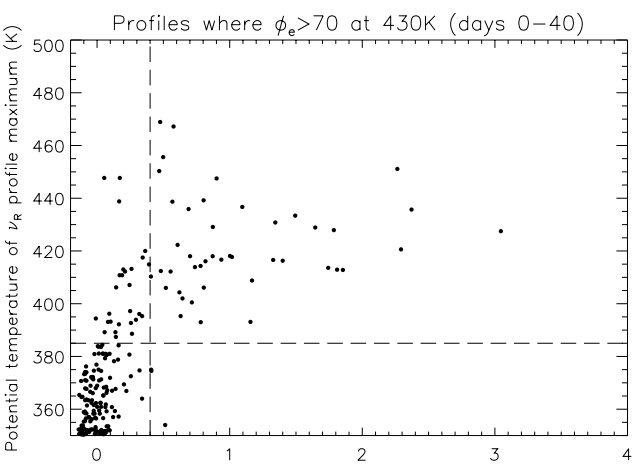

a)

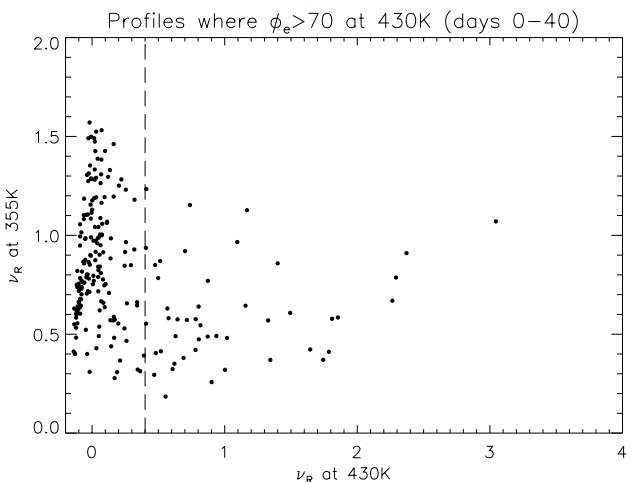

c)

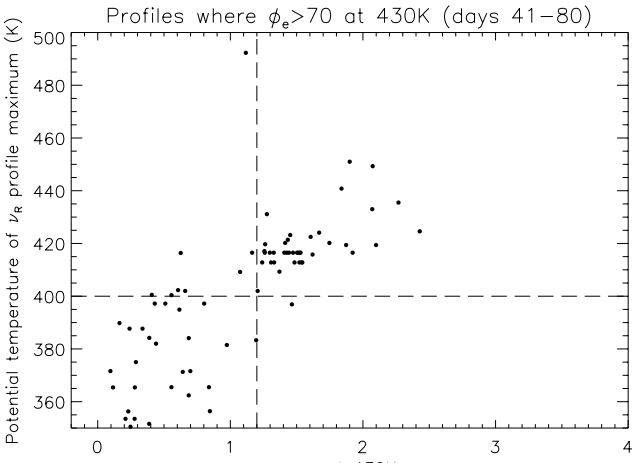

d)

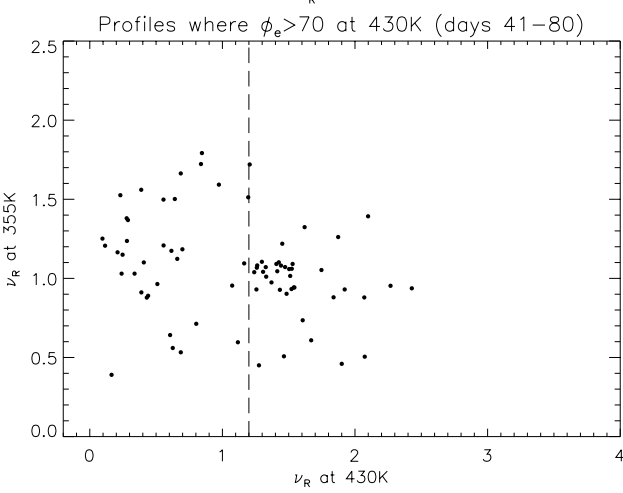

f)

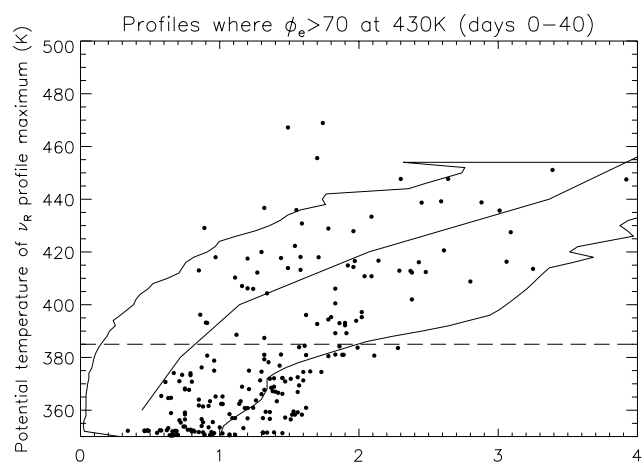

b)

$\nu_{R}$ profile maximum (solid line: $\nu_{R}$ mid-latitude mean)

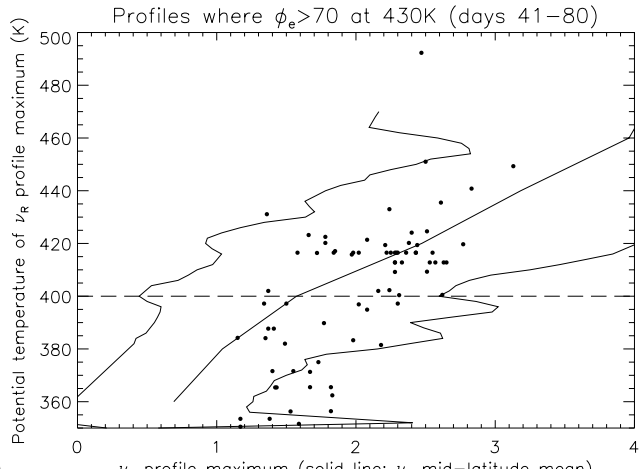

e)

$\nu_{R}$ profile moximum (solid line: $\nu_{R}$ mid-latitude mean)

Fig. 3. Classifying the days profiles that have $\phi_{e}>70$ at $430 \mathrm{~K}$. (a-c): days $0-40 ;(\mathbf{d}-\mathbf{f})$ : days $41-80$. Profiles are characterised by: $v_{R}$ at $430 \mathrm{~K}$; the $v_{R}$ profile maximum; the potential temperature at which the $v_{R}$ profile maximum occurs; and $v_{R}$ at $355 \mathrm{~K}$. The three plots use these values as axes. (a) and (d): potential temperature of the $v_{R}$ profile maximum versus $v_{R}$ at $430 \mathrm{~K}$. (b) and (e): potential temperature of the $v_{R}$ profile maximum versus $v_{R}$ profile maximum value. (c) and (f): $v_{R}$ at $355 \mathrm{~K}$ versus $v_{R}$ at $430 \mathrm{~K}$. In (b) and (e), the profiles of the midlatitude mean, minima and maxima are plotted as solid lines. See text for details, including explanation of the dashed guide lines. 
broad form of $v_{R}$ versus $\phi_{e}$, and the temporal evolution after day 40 should be recalled from Figs. 1 and 2. To classify the profiles into groups, empirical parameters $\theta^{(i)}$ and $v_{R}^{(i)}$ were chosen for each time bin. These thresholds are marked in Fig. 3 by dashed guide lines, and are explained below.

From the correlation plots, and remembering that the plots show data only for those soundings for which $\phi_{e}>70$ at $430 \mathrm{~K}$, the following summary can be made:

For soundings with $v_{R}$ at $430 \mathrm{~K}$ greater than $v_{R}^{(i)}: v_{R}$ at $355 \mathrm{~K}$ is not large (Figs. $3 \mathrm{c}$ and $3 \mathrm{f}$ ); the $v_{R}$ peaks are above $\theta^{(i)}$ (Figs. 3a and 3d); and the $v_{R}$ peak values are almost all consistent with midlatitude observations (Figs. $3 \mathrm{~b}$ and $3 \mathrm{e}$ ).

For soundings with $v_{R}$ at $430 \mathrm{~K}$ less than $v_{R}^{(i)}: v_{R}$ at $355 \mathrm{~K}$ may be large (Figs. 3c and 3f); the $v_{R}$ peaks are mostly below $\theta^{(i)}$ (Figs. 3a and 3d); and a significant proportion of these peak values are inconsistent with midlatitude observations (Figs. $3 b$ and $3 e$ ).

In other words, those lidar soundings for which $\phi_{e}>70$ at $430 \mathrm{~K}$ may be divided into two groups, according to the value of $v_{R}$ at $430 \mathrm{~K}$. Those soundings with large $v_{R}$ at $430 \mathrm{~K}$ show air of midlatitude character at higher $\theta$. They also tend to show relatively low values of $v_{R}$ at $355 \mathrm{~K}$. It was shown earlier that near $355 \mathrm{~K}$ the highest values of $v_{R}$ are generally found where $\phi_{e}>70$. (This is particularly clear for days $0-40$ in Fig. 1. For days $41-80$ the sampling of high equivalent latitudes is rather sparse.) On the other hand, those soundings with smaller $v_{R}$ at $430 \mathrm{~K}$ tend to not sample midlatitudetype air at higher $\theta$, and show relatively large values of $v_{R}$ at $355 \mathrm{~K}$. Therefore, in our set of lidar soundings for which $\phi_{e}>70$ at $430 \mathrm{~K}$, those profiles with large $v_{R}$ at $430 \mathrm{~K}$ appear to sample air of more midlatitude character at both higher and lower altitudes - and therefore are probably sampling air of more midlatitude character at $430 \mathrm{~K}$ also. That is, high values of $v_{R}$ at $430 \mathrm{~K}$ appear to be just signatures of air of midlatitude or at least intermediate (between mid- and high latitude) character. Therefore, our equivalent latitude tracer is unsuccessful at separating mid-latitude or intermediate air from high latitude air at $430 \mathrm{~K}$. So, the large scatter in $v_{R}$ for $\phi_{e}>70$ near $430 \mathrm{~K}$ is down to error in $\phi_{e}$.

The above characteristics are also apparent if the NyÅlesund data is examined on its own, and the clustering in Fig. 3f is clearer when just the Ny-Ålesund data is considered. Thus, systematic differences between stations are not responsible for the above results.

\subsection{Estimating $v_{R}^{(h)}$}

It has been shown in the previous section that at high equivalent latitudes, $\phi_{e}$ is unable to separate pure high latitude air from intermediate or mid-latitude air. An average of $v_{R}$ at large $\phi_{e}$, then, will include intermediate or midlatitude air as well as true high latitude air, and therefore be biased. It is clear from Fig. 1 that at $430 \mathrm{~K}$, the lowest $v_{R}$ values represent samples of the highest true equivalent latitudes. There- fore, near $430 \mathrm{~K}$, the $v_{R}$ minimum may be used as a basis to estimate $v_{R}^{(h)}$. Since random measurement error is a factor, $v_{R}^{(h)}$ may be estimated by the $v_{R}$ minimum plus a suitable correction. At lower potential temperatures, the largest $v_{R}$ values represent samples of the highest true equivalent latitudes (e.g. see Fig. 1, below $380 \mathrm{~K}$ for days 41-80). There, the $v_{R}$ maximum may be used, with a similar correction, to estimate $v_{R}^{(h)}$. The horizontal bars in Fig. 2 show where the minimum or maximum $v_{R}$ is most appropriate for estimating $v_{R}^{(h)}$.

A reasonable approximate correction would be twice the measurement error standard deviation. For Gaussian error statistics, points outside two standard deviations are very obvious outliers. There exist much more rigorous and complex extreme-value theories for modelling minima or maxima of datasets; however in this case the measurement error standard deviation is known only approximately, so a twostandard deviation correction is sufficient for our purposes. Measurement error is 10-20\% in $\mathrm{R}$ ( $\mathrm{R}$ being $v_{R}+1$ ), so the correction $\left(\iota_{v}\right)$ would be $20-40 \%$ in R. $\iota_{v}$ can also be estimated directly from the ratio of maximum and minimum $v_{R}$ at midlatitude. The values obtained are indeed between $20-40 \%$ in R, once any resolved midlatitude gradient of $v_{R}$ with $\phi_{e}$ is removed. The variability could be attributed to unresolved midlatitude gradients, which would cause overestimates. The value of $40 \%$ in $\mathrm{R}$ then is used as an upper bound for the correction $\iota_{\nu}$.

At higher potential temperatures, the value of $v_{R}^{(h)}$ may be estimated fairly straightforwardly, because the observations sampling the highest true equivalent latitudes form an obvious dense cluster around $v_{R} \approx 0$ (see Fig. 1). Figure 4 plots frequency distributions of $v_{R}$, showing that this is true as low as about $400 \mathrm{~K}$ for day $0-40$, and about $480 \mathrm{~K}$ for days $41-$ 80 . Thus, above these potential temperature levels, $v_{R}^{(h)}$ may be conservatively estimated at between $0-0.1$. This also offers another opportunity to estimate $\iota_{\nu}$, as both $v_{R}^{(h)}$ and the observed minimum $v_{R}$ are known in these regions. This gives $\iota_{v} \approx 15 \%$ in $\mathrm{R}$ as corresponding to lower $\phi_{e}$ error.

Thus to estimate $v_{R}^{(h)}$, the profiles can be divided into three potential temperature intervals, each requiring a slightly different method for the estimation of $v_{R}^{(h)}$. The higher potential temperatures were dealt with above. At intermediate altitudes the $v_{R}$ minimum is used, and at lower $\theta$ the $v_{R}$ maximum is used - with a correction to the latter two. For each day range there is an interval where two methods overlap as $v_{R}^{(h)}$ approaches zero. Of the two possible error estimates, the largest is used. Differences in the best estimate of $v_{R}^{(h)}$ are negligible. 
Days 0-40

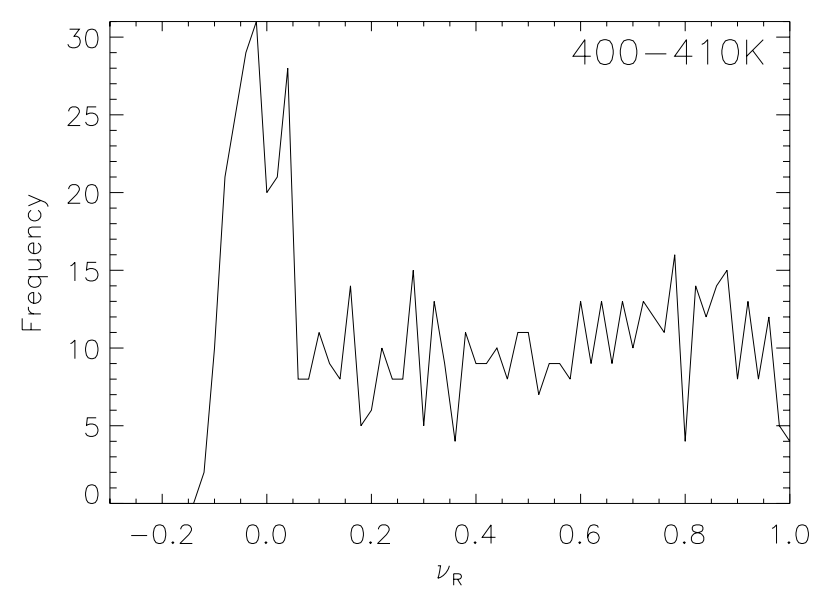

Days $41-80$

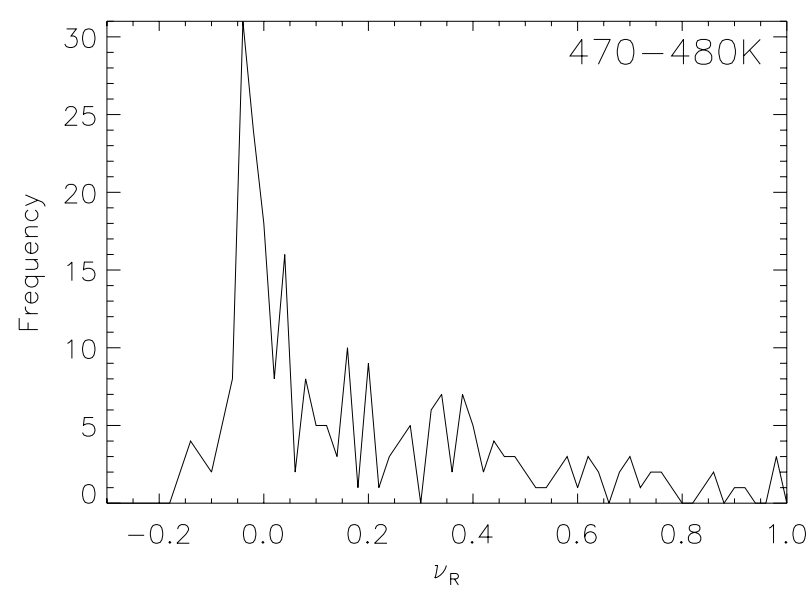

Fig. 4. Frequency distribution of $v_{R}$, for data selected where $\phi_{e}>70$. Bin size is uniform at 0.04 in $v_{R}$.

\section{Results: best estimates of $v_{R}^{(h)}$}

Figures 5 and 6 show estimates for $v_{R}^{(h)}$, as curves drawn over scatter plots of the high- $\phi_{e}$ data. The three methods of estimating $v_{R}^{(h)}$, their parameters, and the potential temperature regions in which they were applied, were described in the previous section. The three lines correspond to zero, low and high $\phi_{e}$ error $\left(\iota_{v}=0,15 \%, 40 \%\right)$. Note that the peak in $v_{R}^{(h)}$ is at a somewhat lower potential temperature than might be guessed from a quick look at the data. Even with a large $\phi_{e}$ error, the scatter plots for $\phi_{e}>80$ would be expected to include a larger proportion of true high latitude observations than those for $\phi_{e}>70$, and indeed the panels for $\phi_{e}>80$ show relatively more observations falling within the estimated $v_{R}^{(h)}$ bounds. This gives more confidence that the $v_{R}^{(h)}$ estimates are representative of true high latitude air.
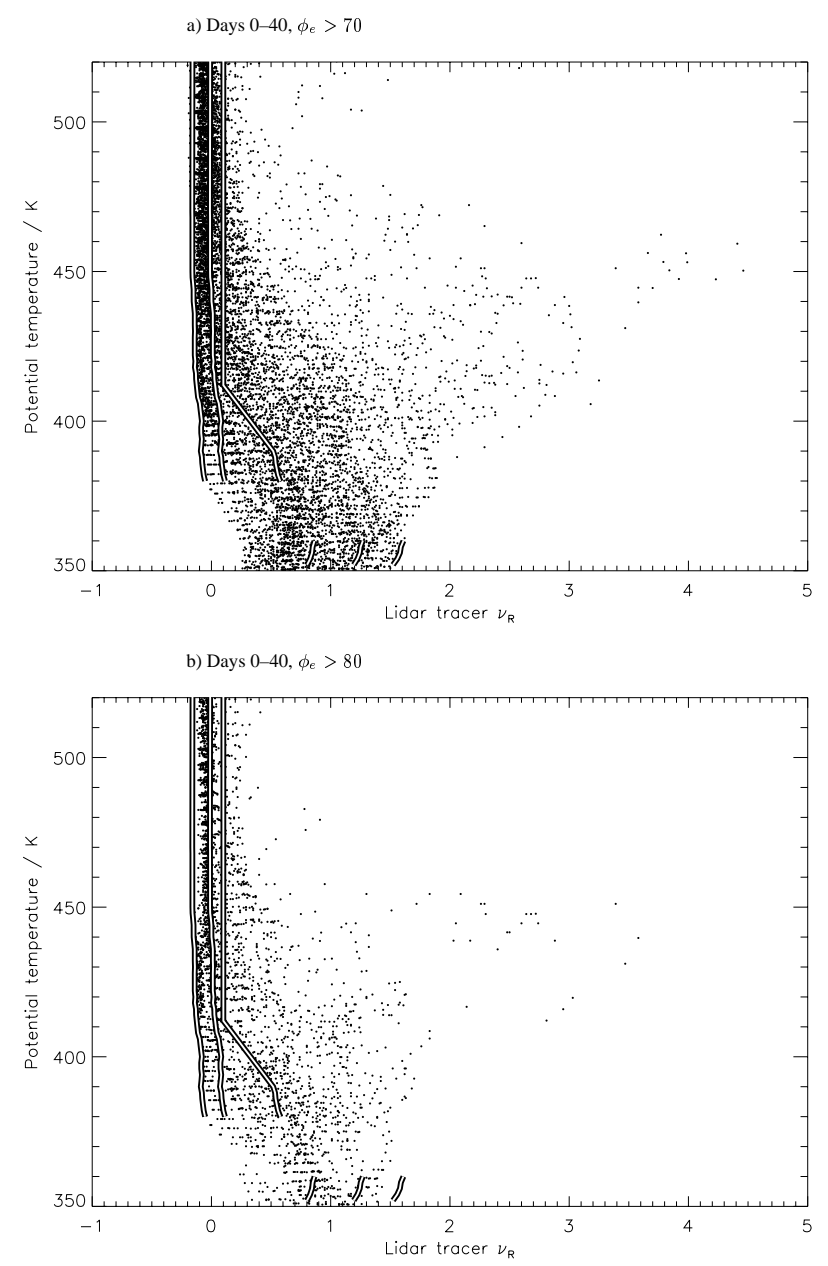

Fig. 5. Potential temperature versus $v_{R}$, for days $0-40$. The scatter plot is the raw data, from (a) $\phi_{e}>70$ and (b) $\phi_{e}>80$. Over-plotted are estimates for $v_{R}^{(h)}$ for zero, medium-low and high $\phi_{e}$ error. $v_{R}^{(h)}$. is the value of $v_{R}$ at the highest true equivalent latitudes - the air most isolated from midlatitude (i.e. deep inside the vortex, where it is present). Note the three lines below $360 \mathrm{~K}$ at $v_{R} \sim 0.8,1.3,1.6$. For $\phi_{e}>80$, a larger proportion of the data falls within the error bounds of $v_{R}^{(h)}$, giving some confidence in the assumptions used in estimating $v_{R}^{(h)}$.

The $v_{R}^{(h)}$ results are quoted for two substantial time bins, but the sporadic nature of the measurement dataset means that we need to be careful about which time period the results are appropriate for. Figure 2 reveals some information about time evolution in $v_{R}^{(h)}$, and measurement frequency, within these rather broad time bins. Note the horizontal bars above and below the data, which indicate whether the $v_{R}$ maximum or minimum is appropriate for estimating $v_{R}^{(h)}$. There is little evolution for days 0-40. After day 40, between about 400$475 \mathrm{~K}$, there is a hint that the evolution in $v_{R}^{(h)}$ is approximately linear. After day 40, most measurements occurred during days 48-62; there were also a few after day 70 . The 

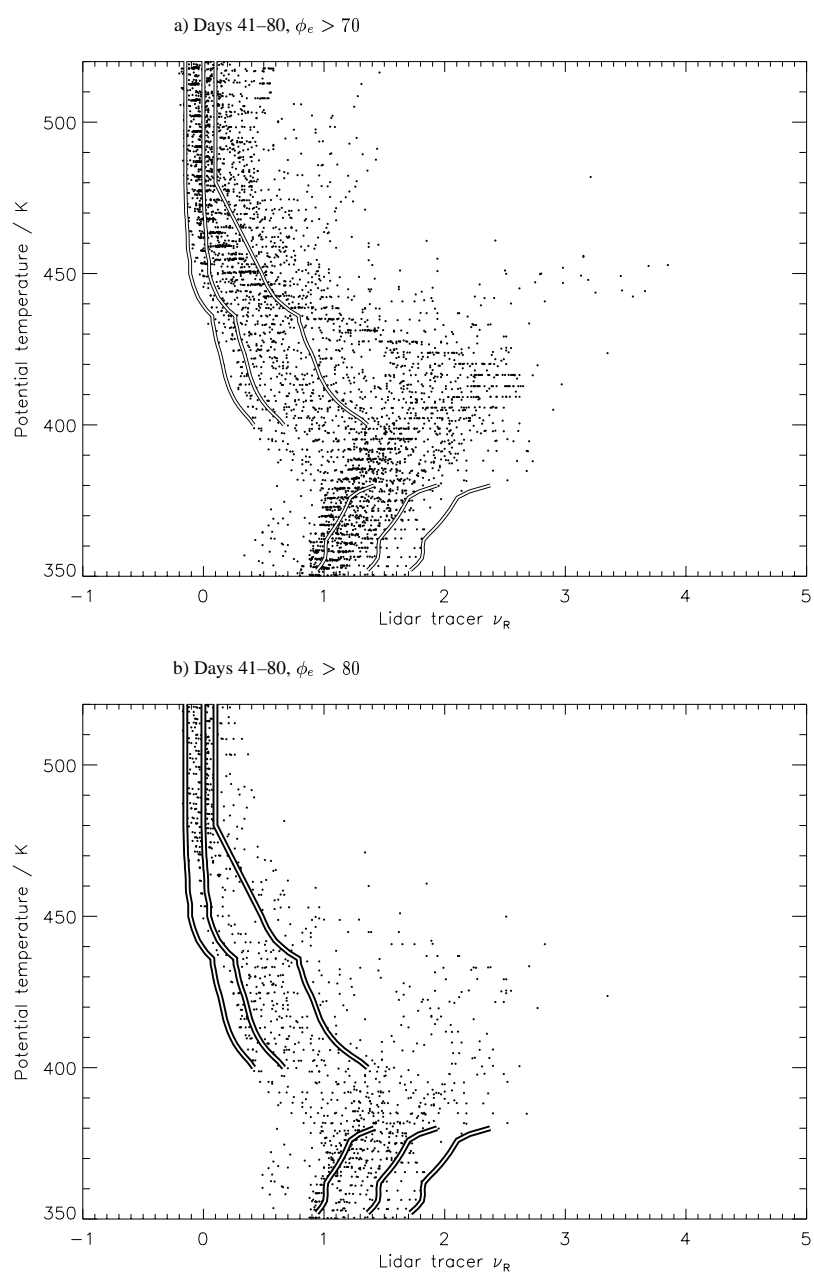

Fig. 6. As Fig. 5, but for days 41-80.

$v_{R}^{(h)}$ results presented here, therefore, apply to days $0-40$ and to days 48-62 (1 January-10 February, and 18 February-2 March).

Figure 7 puts the profile and evolution of $v_{R}^{(h)}$ in perspective, alongside the mean midlatitude vertical profile $\left(v_{R}^{(m)}\right)$. Above $475 \mathrm{~K}$, through days $0-80, v_{R}^{(h)}$ is less than 0.1. Near $475 \mathrm{~K}$, for days $0-62, v_{R}^{(h)} / v_{R}^{(m)}$ is less than $1 / 40$. These indicate a very well isolated vortex centre at this level and above. Between about $475 \mathrm{~K}$ and $410 \mathrm{~K}$, extreme high latitude air is clean of aerosol for the first 40 days, but then sees significant transport of aerosol tracer from lower latitude. This transport increases strongly with decreasing $\theta$. Lower down, there appears to be little barrier between mid- and high latitudes throughout the time studied. This presumably corresponds to the sub-vortex (McIntyre, 1995).
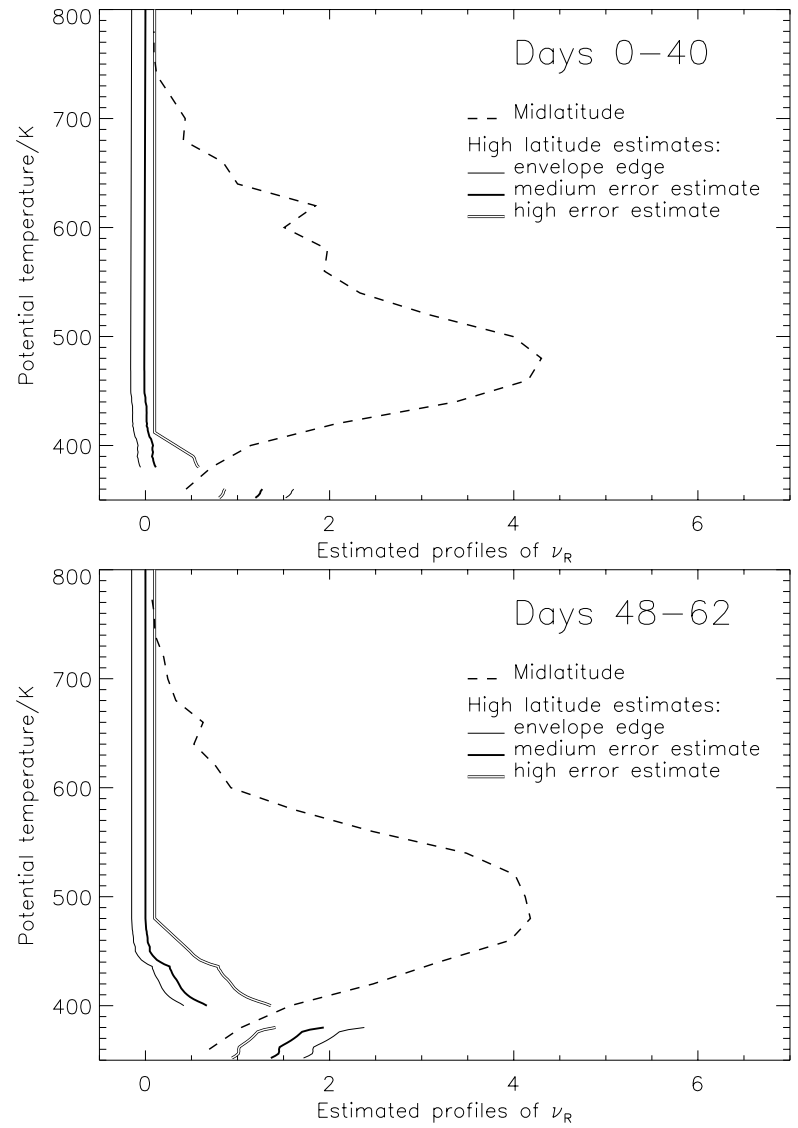

Fig. 7. Estimated mid- and high equivalent latitude vertical profiles of $v_{R}$. (Note the short lines between $350-360 \mathrm{~K}$ ). A very strongly isolated vortex is demonstrated for potential temperatures above about $475 \mathrm{~K}$, but rapidly increasing poleward transport is found below this $\theta$ level. At very low $\theta$ the high latitude $v_{R}$ is larger than the mid-latitude profile, due to stronger diabatic descent over the pole. Above about $500 \mathrm{~K}$ the apparent evolution in the midlatitude profile is partly due to an inability to completely separate midlatitude from tropical observations.

\section{Conclusions}

The results show evidence for irreversible transport of aerosol to the highest equivalent latitudes, resolved in potential temperature and time. Note that the results apply just to the hightest equivalent latitudes, but they are a new part of the high latitude picture for this period. The $v_{R}^{(h)}$ profiles do not have high precision in $v_{R}$, but better accuracy than if the data had been averaged. Quite precise information has been extracted about the temporal evolution and the vertical structure. The EASOE lidar data provided an excellent dataset for this purpose, with a very large number of high resolution observations. 
$v_{R}^{(h)}$ only increases where aerosol has mixed down to the highest equivalent latitudes. Where the vortex is present, this means that aerosol must mix down throughout the vortex centre. Plumb et al. (1994) demonstrated a vortex intrusion event (in measurements and a model), which started on about 19 January (day 18). They also found intrusions in mid-December and mid- to late February. The February event started on day 45 , which seems too late to cause an increase in $v_{R}^{(h)}$ by day 48 . The increase in $v_{R}^{(h)}$ started between days 40-48: 22-30 days after the January intrusion started. If wintertime surf-zone mixdown times (Thuburn and Tan (1997) have 9 days for an order of magnitude reduction in scale) are used, the time taken to mix down from scales the size of the vortex centre (about $6000 \mathrm{~km}$ ) to the lidar resolution (150-200 $\mathrm{m}$ in the vertical: corresponding to about $37.5-50 \mathrm{~km}$ horizontally, using the horizontal/vertical scale ratio of 250 (Haynes and Anglade, 1997)) is about 20 days. Thus, it seems reasonable to make a tentative link between the January intrusion reported by Plumb et al. (1994) and the subsequent increase in $v_{R}^{(h)}$ diagnosed here.

Aerosol sedimentation must be borne in mind with regard to these results. Over the estimated vortex mix-down period of less than one month, below about $450 \mathrm{~K}$ the Pinatubo aerosol would fall only of the order of $10 \mathrm{~K}$ (the lidar resolution is about $4 \mathrm{~K}$ ). This is not important in terms of the vertical precision of the quoted $v_{R}^{(h)}$ results. Sedimentation through vertically sloping transport barriers, could enhance the dispersal of aerosol in equivalent latitude. Pinatubo sedimentation rates in this region are estimated at about $17 \mathrm{~m}$ per day, which is similar to or less than the scale mixed by turbulent dispersion per day. Thus, sedimentation could affect the efficiency of the chaotic mixdown-turbulent dispersion mechanism. Thus, these $v_{R}^{(h)}$ results presumably overestimate the transport that would have occurred for a gaseous tracer.

For future work, Allen and Nakamura (2003) demonstrate a new method for calculating a PV-like tracer which may be smoother at high latitude, and potentially lead to lower equivalent latitude errors in this region.

Edited by: K. Hamilton

\section{References}

Allen, D. R. and Nakamura, N.: Tracer equivalent latitude: A diagnostic tool for isentropic transport studies, J. Atmos. Sci., 60, 287-304, 2003.

Beyerle, G. and Neuber, R.: The stratospheric aerosol content above Spitsbergen during winter 1991/92, Geophys. Res. Lett., 21, 1291-1294, 1994.

Bluth, G. J. S., Doiron, S. D., Schnetzler, C. C., Krueger, A. J., and Walter, L. S.: Global tracking of the $\mathrm{SO}_{2}$ clouds from the June, 1991 MountPinatubo eruptions, Geophys. Res. Lett., 19, 151-154, 1992.
Bohren, C. and Huffman, D.: Scattering and Absorption of Light by Small Particles, Wiley, New York, 1981.

Brock, C. A., Jonsson, H. H., Wilson, J. C., Dye, J. E., Baumgardner, D., Borrmann, S., Pitts, M. C., Osborn, M. T., Decoursey, R. J., and Woods, D. C.: Relationships between optical extinction, backscatter and aerosol surface and volume in the stratosphere following the eruption of Mt-Pinatubo, Geophys. Res. Lett., 20, 2555-2558, 1993.

Browell, E. V., Butler, C. F., Ismail, S., Robinette, P. A., Carter, A. F., Higdon, N. S., Toon, O. B., Schoeberl, M. R., and Tuck, A. F.: Airborne lidar observations in the wintertime Arctic stratosphere - polar stratospheric clouds, Geophys. Res. Lett., 17, 385-388, 1990.

Butchart, N. and Remsberg, E. E.: The area of the stratospheric polar vortex as a diagnostic for tracer transport on an isentropic surface, J. Atmos. Sci., 43, 1319-1339, 1986.

Chazette, P., David, C., Lefrere, J., Godin, S., Pelon, J., and Megie, G.: Comparative lidar study of the optical, geometrical, and dynamical properties of stratospheric post-volcanic aerosols, following the eruptions of El-Chichon and Mount-Pinatubo, J. Geophys. Res.-Atmos., 100, 23 195-23 207, 1995.

Chipperfield, M. P.: Multiannual simulations with a threedimensional chemical transport model, J. Geophys. Res., 104, 1781-1805, 1999.

Chipperfield, M. P. and Jones, R. L.: Relative influences of atmospheric chemistry and transport on Arctic ozone trends, Nature, 400, 551-554, 1999.

Deshler, T.: In-situ measurements of Pinatubo aerosol over Kiruna on 4 days between 18 January and 13 February 1992, Geophys. Res. Lett., 21, 1323-1326, 1994.

Deshler, T., Hofmann, D. J., Johnson, B. J., and Rozier, W. R.: Balloon-borne measurements of the Pinatubo aerosol size distribution and volatility at Laramie, Wyoming during the summer of 1991, Geophys. Res. Lett., 19, 199-202, 1992.

Deshler, T., Johnson, B. J., and Rozier, W. R.: Balloonborne measurements of Pinatubo aerosol during 1991 and 1992 at 41degrees-N - vertical profiles, size distribution, and volatility, Geophys. Res. Lett., 20, 1435-1438, 1993.

Digirolamo, P., Cacciani, M., Disarra, A., Fiocco, G., and Fua, D.: Lidar observations of the Pinatubo aerosol layer at Thule, Greenland, Geophys. Res. Lett., 21, 1295-1298, 1994.

Farman, J. C., Oneill, A., and Swinbank, R.: The dynamics of the arctic polar vortex during the EASOE campaign, Geophys. Res. Lett., 21, 1195-1198, 1994.

G. Brasseur, J. O. and Tyndall, G.: Atmospheric Chemistry and Global Change, Oxford University Press, New York, 1999.

Good, P. and Pyle, J.: Refinements in the use of equivalent latitude for assimilating sporadic inhomogeneous stratospheric tracer observations, 1: Detecting transport of Pinatubo aerosol across a strong vortex edge, Atmos. Chem. Phys. Discuss., Vol. 4, 635666, 29-1-200420042, 2004

Grant, W. B., Browell, E. V., Long, C. S., Stowe, L. L., Grainger, R. G., and Lambert, A.: Use of volcanic aerosols to study the tropical stratospheric reservoir, J. Geophys. Res.-Atmos., 101, 3973-3988, 1996.

Hanson, D. R., Ravishankara, A. R., and Solomon, S.: Heterogeneous reactions in sulfuric-acid aerosols - a framework for model-calculations, J. Geophys. Res.-Atmos., 99, 3615-3629, 1994. 
Haynes, P. and Anglade, J.: The vertical-scale cascade in atmospheric tracers due to largescale differential advection, J. Atmos. Sci., 54, 1121-1136, 1997.

Jager, H., Deshler, T., and Hofmann, D. J.: Midlatitude lidar backscatter conversions based on balloonborne aerosol measurements, Geophys. Res. Lett., 22, 1729-1732, 1995.

Langford, A. O., Oleary, T. J., Proffitt, M. H., and Hitchman, M. H.: Transport of the Pinatubo volcanic aerosol to a northern midlatitude site, J. Geophys. Res.-Atmos., 100, 9007-9016, 1995.

Lee, A. M., Roscoe, H. K., Jones, A. E., Haynes, P. H., Shuckburgh, E. F., Morrey, M. W., and Pumphrey, H. C.: The impact of the mixing properties within the Antarctic stratospheric vortex on ozone loss in spring, J. Geophys. Res.-Atmos., 106, 3203-3211, 2001.

Manney, G. L., Bird, J. C., Donovan, D. P., Duck, T. J., Whiteway, J. A., Pal, S. R., and Carswell, A. I.: Modeling ozone laminae in ground-based Arctic wintertime observations using trajectory calculations and satellite data, J. Geophys. Res.-Atmos., 103, 5797-5814, 1998.

Massie, S. T., Dye, J. E., Baumgardner, D., Randel, W. J., Wu, F., Tie, X. X., Pan, L. W., Figarol, F., Brasseur, G. P., Santee, M. L., Read, W. G., Grainger, R. G., Lambert, A., Mergenthaler, J. L., and Tabazadeh, A.: Simultaneous observations of Polar Stratospheric Clouds and $\mathrm{HNO}_{3}$ over Scandinavia in January, 1992, Geophys. Res. Lett., 24, 595-598, 1997.

McCormick, M. P. and Veiga, R. E.: SAGE-II measurements of early Pinatubo aerosols, Geophys. Res. Lett., 19, 155-158, 1992.

McIntyre, M. E.: The stratospheric polar vortex and sub-vortex fluid-dynamics and midlatitude ozone loss, Philos. Trans. R. Soc. Lond. Ser. A-Math. Phys. Eng. Sci., 352, 227-240, 1995.

Millard, G. A., Lee, A. M., and Pyle, J. A.: A model study of the connection between polar and midlatitude ozone loss in the Northern Hemisphere lower stratosphere, J. Geophys. Res.Atmos., 108, art. no.-8323, 2002.

Nakamura, N.: Two-dimensional mixing, edge formation, and permeability diagnosed in an area coordinate, J. Atmos. Sci., 53, 1524-1537, 1996.

Neuber, R., Beyerle, G., Fiocco, G., Disarra, A., Fricke, K. H., David, C., Godin, S., Knudsen, B. M., Stefanutti, L., Vaughan, G., and Wolf, J. P.: Latitudinal distribution of stratospheric aerosols during the EASOE winter 1991/92, Geophys. Res. Lett., 21, 1283-1286, 1994.

Plumb, R. A. and Ko, M. K. W.: Interrelationships between mixing ratios of long lived stratospheric constituents, J. Geophys. Res.Atmos., 97, 10 145-10 156, 1992.
Plumb, R. A., Waugh, D. W., Atkinson, R. J., Newman, P. A., Lait, L. R., Schoeberl, M. R., Browell, E. V., Simmons, A. J., and Loewenstein, M.: Intrusions into the lower stratospheric arctic vortex during the winter of 1991-1992, J. Geophys. Res.-Atmos. 99, 1089-1105, 1994.

Plumb, R. A., Waugh, D. W., and Chipperfield, M. P.: The effects of mixing on traces relationships in the polar vortices, J. Geophys. Res.-Atmos., 105, $10047-10062,2000$.

Prather, M. J.: Numerical advection by conservation of 2 nd-order moments, J. Geophys. Res., 91, 6671-6681, 1986.

Read, W. G., Froidevaux, L., and Waters, J. W.: Microwave Limb Sounder measurement of stratospheric $\mathrm{SO}_{2}$ from the MtPinatubo volcano, Geophys. Res. Lett., 20, 1299-1302, 1993.

Russell, J. M., Gordley, L. L., Park, J. H., Drayson, S. R., Hesketh, W. D., Cicerone, R. J., Tuck, A. F., Frederick, J. E., Harries, J. E., and Crutzen, P. J.: The halogen occultation experiment, J. Geophys. Res., 98, 10777-10 797, 1993.

Russell, P. B., Livingston, J. M., Pueschel, R. F., Bauman, J. J., Pollack, J. B., Brooks, S. L., Hamill, P., Thomason, L. W., Stowe, L. L., Deshler, T., Dutton, E. G., and Bergstrom, R. W.: Global to microscale evolution of the Pinatubo volcanic aerosol derived from diverse measurements and analyses, J. Geophys. Res.-Atmos., 101, 18 745-18 763, 1996.

Schafer, H. J., Scheuch, P., Langer, M., Fricke, K. H., Vonzahn, U., and Knudsen, B. M.: Lidar observations of polar stratospheric clouds at Andoya, Norway, in January 1992, Geophys. Res. Lett., 21, 1307-1310, 1994.

Steele, H. M. and Hamill, P.: Effects of temperature and humidity on the growth and opticalproperties of sulfuric acid-water droplets in the stratosphere, J. Aerosol. Sci., 12, 517-528, 1981.

Stein, B., Delguasta, M., Kolenda, J., Morandi, M., Rairoux, P., Stefanutti, L., Wolf, J. P., and Woste, L.: Stratospheric aerosolsize distributions from multispectral lidar measurements at Sodankyla during EASOE, Geophys. Res. Lett., 21, 1311-1314, 1994.

Swinbank, R. and O'Neill, A.: A stratosphere troposphere data assimilation system, Monthly Weather Review, 122, 686-702, 1994.

Thuburn, J. and Tan, D. G. H.: A parameterization of mixdown time for atmospheric chemicals, J. Geophys. Res.-Atmos., 102, 13 037-13 049, 1997.

Trepte, C. R., Veiga, R. E., and McCormick, M. P.: The poleward dispersal of Mount-Pinatubo volcanic aerosol, J. Geophys. Res.Atmos., 98, 18 563-18 573, 1993.

Vaughan, G., Wareing, D. P., Jones, S. B., Thomas, L., and Larsen, N.: Lidar measurements of Mt-Pinatubo aerosols at Aberystwyth from August 1991 through March 1992, Geophys. Res. Lett., 21, 1315-1318, 1994. 